MATEC Web of Conferences 23,01053 (2015)

DOI: $10.1051 /$ matecconf/ 20152301053

(C) Owned by the authors, published by EDP Sciences, 2015

\title{
EXPERIMENTAL RESEARCH OF MOISTURE EVAPORATION PROCESS FROM BIOMASS IN A DRYING CHAMBER
}

\author{
Bulba E.E., Malinovsky A.A. \\ Tomsk Polytechnic University, 634050 Tomsk, Russian
}

\begin{abstract}
Presented mass evaporation rate hardwood (birch, aspen, maple, poplar) derived from experimental studies. The dependence of temperature on evaporation mass rate and calculated the accommodation coefficient for the respective temperature ranges are obtained. Analyzed the temperature of drying conditions relevant species hardwood.
\end{abstract}

\section{Introduction}

Biomass is a promising material for power system [1]. Perhaps as a direct burning different kinds of biofuels and use for the production of biogas and other resources [2]. However, conversion biomass conjugate always, regardless of the form of the final product, with the preparation of biomass for processing. The main element of this training is drying [3], to carry out energy, which is usually high [4]. Therefore, optimization of technology is one of the tasks, without which it is impossible to actual use of biomass not only in the energy sector but also in other industries.

The problem of drying is being developed for many decades [5], but so far, we cannot say that developed the general theory that provides the ability to forecast the main characteristics of this process in concrete terms. This is largely due to the fact that is not yet developed to a sufficient level for practical use of the theoretical foundations of the evaporation of liquids. In most applications used in describing the various fluids of the evaporation process a mathematical expression law HertzKnudsen (e.g. [6-8]), which does not always match the actual processes as the removal of moisture from the surface and pore structure of water-containing substance or material. For these reasons, a pilot study is currently the main tool for studying basic laws of processes remove moisture from porous materials, including woody biomass.

\section{Experimental procedure}

Experimental studies conducted using a heating chamber into which the container-controlled area of evaporation, the mass of which is determined with the help of laboratory scales. Samples placed in a vessel timber. The samples of birch, maple, poplar, aspen. Electric contact thermometer, the temperature was controlled in the heat chamber. It measures the atmospheric pressure and humidity under which conducted the experimental study. The meter is set to "temperature measurement", the thermocouple was placed in the sample and included a heat chamber. Upon reaching a temperature equal to the temperature in the vessel in the heating chamber, the vessel was removed from the sample timber and the weight was measured. The vessel was placed in the biomass heat chamber and the experiment was conducted. At the end of a given period of time the vessel was weighed, and the amount of evaporated liquid. The experiment was repeated at least 3 times a constant temperature in the chamber at a predetermined interval of time. Heating was provided wire heaters placed on the heating circuit. 
In its lower part it is arranged air ducts for supply of cold air. The intensity of the ventilation adjusted lower ventilation flap. In the upper part of the working chamber located holes temperature measuring device and to reset moisture vapor. The basic quantities characterizing the process of evaporation, phase transition was the speed, the surface area of the liquid, which evaporates, and the temperature. The first characteristic determined by the surface density of the steam flow supplied per unit time in the gas phase with a unit surface of the liquid. Investigations of the mass evaporation rate of the samples in the large intervals of time at various temperatures to a reasonable conclusion about the steady-state process of evaporation of the liquid in the conditions of experiments performed. Selecting objects of research due to the prevalence of most of these species of hardwood in the Russian Federation. Calculations accommodation coefficient, which characterizes the number of molecules of steam coming off the surface evaporation.

\section{RESULTS AND DISCUSSION}

By analyzing the results (Fig. 1), it can be concluded that the mass evaporation rate of all the samples of wood over time does not change. Apparently the transfer of moisture from the interior to the surface layers of hardwood in the test temperature range is a stationary process.

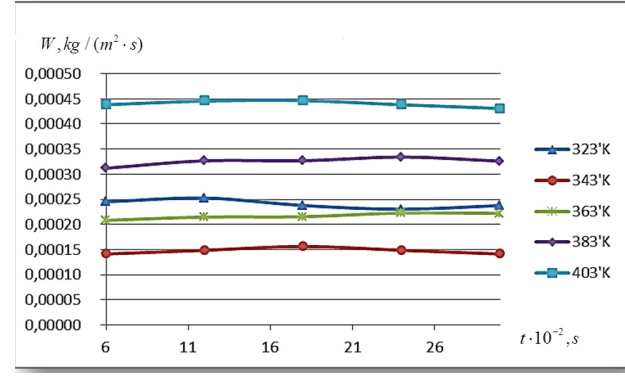

a)

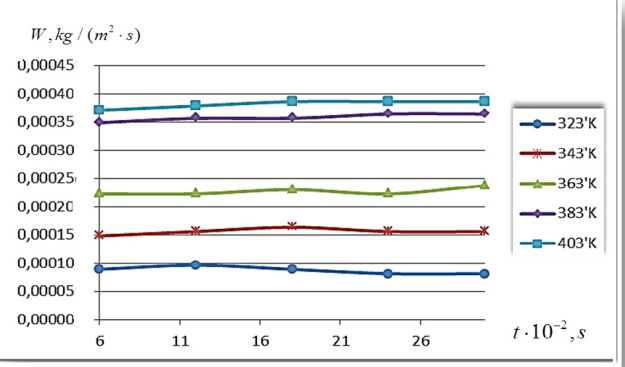

c)

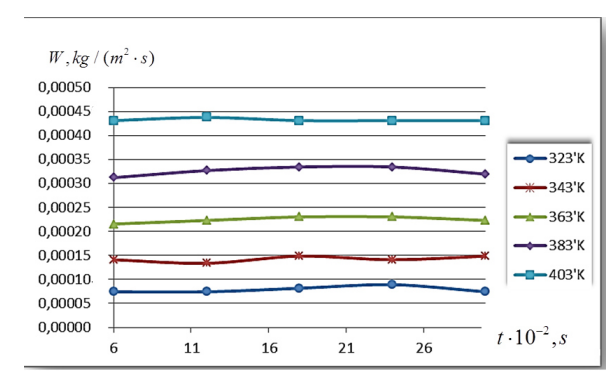

b)

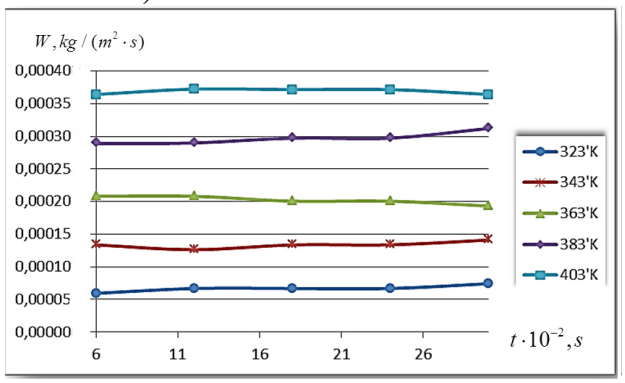

d)

Fig. 1. Dependence of the mass evaporation rate from the time the four types of biomass: a) maple; b) - poplar; c) - birch; d) - aspen

Here $\mathrm{T}$ - temperature heat chamber, $\mathrm{t}$ - duration of the experiment, wisp - a massive rate of evaporation of the liquid.

In the next phase of experiments obtained dependence mass evaporation rate of temperature.

The figure shows the experimental results when heating in the range of $323 \mathrm{~K}$ to $403 \mathrm{~K}$ at a rate depending on the phase transition temperature. Confidence intervals are given characterizing error measurements. 

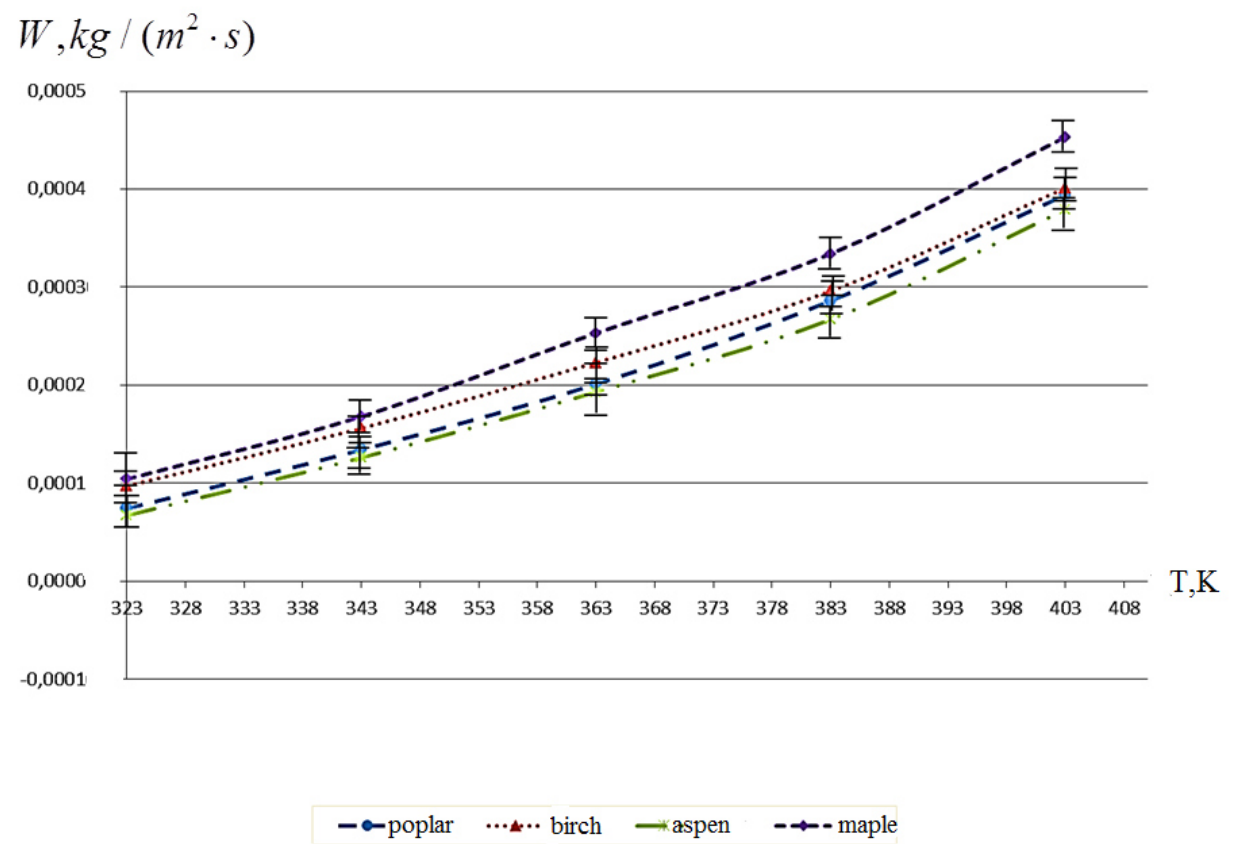

Fig.2. The dependence of the mass evaporation rate of the samples of wood temperature

The highest rate of evaporation of liquid from the set of samples of maple and birch. Caloric value of these types of timber above $(10550 \mathrm{~kJ} / \mathrm{kg}$ and $9504 \mathrm{~kJ} / \mathrm{kg})$ than in aspen and poplar $(7578 \mathrm{~kJ} / \mathrm{kg}$ and $7033 \mathrm{~kJ} / \mathrm{kg}$ ), respectively.

Processing the results of experiments carried out using well-established techniques [9]. For each value of the temperature over a given time interval $(\mathrm{t}=10 \mathrm{~min}$.) was carried out on five dimensions. Depending on the experimental W $(\mathrm{T})$ is designed accommodation coefficient, which depends on the nature and state of the surface, as well as the properties of the vapor and the temperature.

Mass rate of evaporation is calculated from the expression for the accommodation coefficient (the law of the Hertz-Knudsen):

$$
A=\frac{W \cdot \sqrt{\frac{2 \pi R T}{M}}}{\left(P^{H}-P^{*}\right)},
$$

where W - the mass evaporation rate, $\mathrm{kg} /(\mathrm{m} 2 \cdot \mathrm{s})$; Pn - vapor pressure, $\mathrm{Pa} ; \mathrm{P} *$ - partial pressure of the volatile component, calculated at a relative humidity of $\varphi=0,5, \mathrm{~Pa} ; \mathrm{R}=8,31$ - universal gas constant, J / ( $\mathrm{mol}-\mathrm{K}) ; \mathrm{M}$ - molecular weight; $\mathrm{T}$ - temperature of the substance, K; A accommodation coefficient.

Table 1 shows the calculated values of accommodation in the temperature range from $323 \mathrm{~K}$ to $403 \mathrm{~K}$ for all studied materials. Experience shows that an increase in temperature of the liquid accommodation coefficient for all four types of biomass decreases. By analyzing the physics of the process of evaporation, it can be assumed that at the boundary of a phase transition of the porous moisture-wood partial pressure of vapor molecules is lower than calculated at the appropriate relative humidity and be used in mathematical expression for calculating the coefficient of accommodation. 
Table 1 is the coefficient of accommodation

\begin{tabular}{|c|c|c|c|c|}
\hline & \multicolumn{4}{|c|}{ The coefficient of accommodation, $\mathrm{A} \cdot 10^{5}$} \\
\hline$T, \mathrm{~K}$ & birch & maple & poplar & aspen \\
\hline 323 & 0,447 & 0,419 & 0,432 & 0,337 \\
\hline 343 & 0,332 & 0,447 & 0,291 & 0,275 \\
\hline 363 & 0,225 & 0,235 & 0,221 & 0,199 \\
\hline 383 & 0,168 & 0,157 & 0,158 & 0,143 \\
\hline 403 & 0,119 & 0,116 & 0,113 & 0,099 \\
\hline
\end{tabular}

\section{Conclusion}

The results of the experimental studies are the basis for further refinement of the mechanism of removing moisture from the porous structure of the water-containing material and the development of the general theory of drying. Dependencies mass evaporation rate of the investigated samples of wood from the temperature was allowed to determine the coefficient of accommodation in the mathematical expression of the law Hertz-Knudsen.

\section{References}

1. Forest bioenergy: Proc. Benefit / YP Semenov [et al.].; ed. Yuri Semenov. - Moscow: State Univ state. Univ forests, 2008. - 348 p. : Ill. - Bibliography .: p. 300-311.

2. Iron TA Geletukha GG, Review of modern technologies of biomass gasification // Industrial Heat Engineering, 2006, №2, p. 61-75.

3. GS Shubin Modes of wood drying and their rational implementation // Industrial Heat Engineering, 2007, №5.

4. Swan DV The use of biofuels. Methodological approaches to the determination of economic efficiency of investments // Industrial Energy 2007, №7, p. 45-47

5. AV Lykov Theory of drying, 2nd edition revised and enlarged, "Energy", Moscow, 1968.$472 \mathrm{~b}$.

6. Kuznetsov G.V., Al-Ani, Sheremet M.A. Numerical analysis of convective heat transfer in a closed two-phase thermosyphon // Journal of Engineering Thermophysics. - 2011. - P.201210.

7. Vysokomornaya OV, Kuznetsov GV, Strizhak PA Heat and mass transfer in the process of movement of water drops in a hightemperature gas medium // Journal of Engineering Physics and Thermophysics. - 2013, - P. 1-7.

8. Kuznetsov G.V., Strizhak P.A. The influence of heat transfer conditions at the hot particleliquid fuel interface on the ignition characteristics // Journal of Engineering Thermophysics. 2009. T. 18. № 2. pp 162-167.

9. VA Arkhipov, Berezikov AP Basic theory of engineering physics experiment. - Tomsk: Publishing House of Tomsk Polytechnic University, in 2008 to -206. 